\title{
BMJ Open Breastfeeding education, early skin-to- skin contact and other strong determinants of exclusive breastfeeding in an urban population: a prospective study
}

Iván Dueñas-Espín (10 , ${ }^{1}$ Ángela León Cáceres (1) , ${ }^{1,2}$ Angelica Álava, ${ }^{3}$ Juan Ayala, ${ }^{4}$ Karina Figueroa, ${ }^{5}$ Vanesa Loor, ${ }^{6}$ Wilmer Loor, ${ }^{7}$ Mónica Menéndez, ${ }^{8}$ David Menéndez, ${ }^{9}$ Eddy Moreira, ${ }^{10}$ René Segovia, ${ }^{11}$ Johanna Vinces ${ }^{12}$

To cite: Dueñas-Espín I, León Cáceres Á, Álava A, et al. Breastfeeding education, early skin-to-skin contact and other strong determinants of exclusive breastfeeding in an urban population: a prospective study. BMJ Open 2021;11:e041625. doi:10.1136/ bmjopen-2020-041625

- Prepublication history and additional materials for this paper is available online. To view these files, please visit the journal online (http://dx.doi. org/10.1136/bmjopen-2020041625).

Received 12 June 2020 Revised 05 January 2021 Accepted 14 January 2021
Check for updates

(c) Author(s) (or their employer(s)) 2021. Re-use permitted under CC BY-NC. No commercial re-use. See rights and permissions. Published by BMJ.

For numbered affiliations see end of article.

Correspondence to Dr. Iván Dueñas-Espín; igduenase@puce.edu.ec

\section{ABSTRACT}

Objective The current study aims to demonstrate independent associations between social, educational and health practice interventions as determinants of exclusive breastfeeding in an urban Ecuadorian population.

Design Prospective survival analyses.

Setting Ecuadorian mother-child dyads in urban settings. Participants We followed-up 363 mother-baby dyads who attended healthcare centres in Portoviejo, province of Manabi, for a median time (P25-P75) of 125 days (121-130 days).

Main outcome measures We performed a survival analysis, by setting the time-to-abandonment of exclusive breastfeeding measured in days of life, that is, duration of exclusive breastfeeding, periodically assessed by phone, as the primary outcome. Crude and adjusted mixedeffects Cox proportional hazards model were performed to estimate HRs for each explanatory variable.

Results The incidence rate of abandonment of breastfeeding was 8.9 per 1000 person-days in the whole sample. Multivariate analysis indicated the three most significant protective determinants of exclusive breastfeeding were (a) sessions of prenatal breastfeeding education with an HR of 0.7 (95\% Cl: 0.5 to 0.9$)$ per each extra session, (b) self-perception of milk production, with an HR of 0.4 ( $95 \% \mathrm{Cl}: 0.3$ to 0.6$)$ per each increase in the perceived quantity of milk production and (c) receiving early skin-to-skin contact with an HR of $0.1(95 \% \mathrm{Cl}$ : $<0.1$ to 0.3 ) compared with those not receiving such contact, immediately after birth.

Conclusions Prenatal education on breastfeeding, selfperception of sufficient breast-milk production and early skin-to-skin contact appear to be strong protectors of exclusive breastfeeding among urban Ecuadorian motherbaby dyads.

\section{INTRODUCTION}

Breastfeeding promotion is a highly costeffective health intervention with individual, social and economic advantages. ${ }^{1}$ Benefits from exclusive breastfeeding have been extensively demonstrated during childhood
Strengths and limitations of this study

- This is a longitudinal prospective study developed under real-life conditions, in an urban Ecuadorian population, in the Coast region, Manabi province.

- A total of 363 mother-baby dyads were followed up for a median time of 125 days, data were collected at three separate times in three different phone surveys.

- A Cox proportional hazards model was performed to evaluate the independent association between each explanatory variable and the duration of exclusive breastfeeding.

- Several secondary analyses to assess the sensitivity of our estimates with our assumptions regarding biases were conducted.

- The most relevant limitation was the lack of representativeness of rural a population, in which determinants are expected to be different.

and adulthood. ${ }^{2-4}$ Mothers who breastfeed have better health outcomes, such as decreased risk of breast and ovarian cancer, and hip fractures, and osteoporosis during post-menopause. $^{5}$

Several social and economic determinants of breastfeeding have been demonstrated ${ }^{6}$; among these, socioeconomic barriers preclude proper breastfeeding for infants and children. ${ }^{6}$ Specifically, Ecuador has experienced several difficulties in implementing policies towards 6 months of exclusive breastfeeding. ${ }^{78}$ There are difficulties in access to services that promote breastfeeding, such as lactation support rooms, milk banks, exposure to edu-communicational interventions for breastfeeding promotion, among others. Furthermore, food and breast-milk substitutes industries have a significant influence 
on breastfeeding decisions, as $18 \%$ of new Ecuadorian mothers participated in industry-sponsored social groups and activities. ${ }^{9}$

As a result, Ecuador has a low rate of 6 months of exclusive breastfeeding according to two massive national surveys. ${ }^{8}$ Although several policies and regulations for healthcare services directed to improve such indicators exist, the majority have not been effectively applied, enhancing the need for additional effort, especially in the healthcare area. ${ }^{10}$ Additionally, in the province of Manabi, there is a $10.2 \%$ rate of illiteracy, the majority of the population has no social insurance, and women are less economically active than men. ${ }^{11}$

In the prenatal, natal and postnatal healthcare areas, several determinants heavily influence the maintenance of breastfeeding. In that sense, the United Nations Children's Fund (UNICEF) and the WHO launched the baby-friendly hospital initiative (BFHI), a strategy at the healthcare level for enhancing good practices towards improved adherence to breastfeeding, which is well recognised as a cost-effective way to promote and protect breastfeeding. ${ }^{12}$ BFHI has been aimed to (a) improve the quality and comprehensiveness of prenatal care, (b) promote humanised delivery and adequate newborn care, (c) improve the quality of care for obstetric and neonatal emergencies, (d) prevent vertical transmission of HIV and syphilis and (e) promote, support and protect breastfeeding.

Specifically, the early skin-to-skin contact strategy has been demonstrated as effective for improving exclusive and nonexclusive breastfeeding rates, ${ }^{13}$ considering it as a strong determinant of breastfeeding. Nevertheless, to the best of our knowledge, this practice has been neither tested nor proven as a determinant of breastfeeding in any Ecuadorian population. Given that Manabi is one of the provinces with a lower prevalence of early initiation of breastfeeding at the national level and considering that the prevalence of early initiation of and exclusive breastfeeding is lower among urban vs rural populations, ${ }^{8}$ we conducted this study to research breastfeeding determinants in an urban population of Portoviejo-Manabi.

Considering current scientific evidence, we hypothesised that sociodemographic, prenatal, natal and puerperal characteristics of the mother-baby dyads would be associated with exclusive breastfeeding maintenance in an urban Ecuadorian population. The current study aims to demonstrate independent associations between sociodemographic characteristics, educational background and health practice interventions as determinants of exclusive breastfeeding in an urban population of Manabi, Ecuador.

\section{METHODS}

\section{Design}

Prospective survival analyses

Population and sample

We initially recruited 400 mother-baby dyads who attended either (a) one hospital or (b) six primary healthcare facilities in Portoviejo, in the province of Manabi. Given that the determinants of breastfeeding are different for premature infants, we excluded from the follow-up those dyads in which the infant was born at $<37$ weeks of gestational age. A total number of 363 dyads were followed up for a median time (P25-P75) of 125 days (121-130 days) (see the study flowchart in online supplemental figure 1S).

We included in the study dyads in which: (a) mothers were at immediate or mediate puerperium, typically from delivery to $<40$ days postpartum and who were exclusively breastfeeding; (b) whose neonates were alive; (c) mothers who were literate and did not have physical, motor, intellectual or visual disabilities and (d) mothers who were not/had previously not been contraindicated to carry out breastfeeding (eg, HIV, active infections of the mammary gland and active pulmonary tuberculosis). We excluded dyads in which: (a) neonates died; (b) mothers who were illiterate and/or had physical, motor, intellectual or visual disabilities; (c) mothers with contraindication to perform breastfeeding and (d) mothers who had not signed the informed consent and/or declined to participate in the study.

\section{Main outcome and other measurements}

We prospectively followed-up the dyads and performed a survival analysis by setting the time-to-abandonment of exclusive breastfeeding measured in days of life (ie, the duration of exclusive breastfeeding). Sociodemographic data and health practice interventions were collected in person during the first visit (performed between delivery to $<40$ days postpartum); then, approximately every 60 days were assessed by phone, the date on which mothers reported that other food or liquid than breast milk was given to the baby, according to the WHO's definition of exclusive breastfeeding. ${ }^{14}$ Therefore, we collected data regarding maintenance of breastfeeding during approximately the second and fourth months post-delivery. Consequently, three different surveys were conducted, one in person and the remaining two by phone.

Several variables were obtained at the first visit: mother's age, marital status, education, employment status, type of health insurance and socioeconomic conditions measured by the Graffar questionnaire. ${ }^{15}$ We used the maternal health card to obtain data regarding prenatal care variables (number of prenatal care office visits, sessions of education about breastfeeding and obstetric risk), natal care such as manner of delivery, healthcare practice during delivery (skin-to-skin contact, joint accommodation, timely ligation of the umbilical cord and breastfeeding within the first hour of life) and infant variables (sex, gestational age, birth weight in grams and self-perception of milk production).

\section{Statistical analyses and sample considerations}

Using early skin-to-skin contact as the main explanatory variable, we performed a sample calculation by using the following parameters: considering that the incidence rate 
of abandonment of exclusive breastfeeding was 2.8 events per 1000 patient-days among those newborns who did not receive early skin-to-skin contact (unexposed). We observed that with an $\alpha=0.05$ (two-tailed) and a $\beta=0.2$, the minimum required number of patients in the group with skin-to-skin contact (exposed) was 204 patients and 42 in the unexposed group. ${ }^{16}$ The final sample constituted 363 dyads, with 302 exposed patients and 61 unexposed patients, assuring statistical power (see online supplemental material for further details).

Descriptive statistics were performed using percentages for categorical variables and median time (P25P75) for discrete variables. We performed log-rank tests for equality of survivor functions to assess differences in duration of exclusive breastfeeding. Then, we estimated crude and adjusted HRs per each explanatory outcome. In that sense, we built multivariate Cox proportional hazards models to evaluate the independent association between each explanatory variable and actual time in days to abandonment of exclusive breastfeeding. We built a saturated model, including all the individual covariates. Then, based on previously established criteria, we eliminated covariates with $p>0.25$ from significant covariates that were retained in the model. ${ }^{17}$ CIs $(95 \%)$ of the HR and their corresponding $\mathrm{p}$ values were calculated. Once the parsimonious model was obtained, we compared both models and chose the 'final' model, according to its level of significance from the likelihood ratio test. To assess effects from socioeconomic levels, we estimated HR by mixed-effects methods from the Cox proportional hazards model. Given the small number of missing data points (there were missing values in $<1 \%$ of the entire database), we employed complete case analysis in estimating statistical associations.

To test for potential effect modification, we stratified the main analysis according to infant sex. Additionally, we performed several secondary analyses to assess the sensitivity of our estimates with our assumptions regarding biases, as well as to test for model misspecifications. First, we stratified by sex of the infant; second, we ran the final model excluding (a) dyads with single mothers, (b) those with no education or only basic education, (c) those dyads from high socioeconomic level and (d) those dyads in which the infant was delivered by a C-section.

\section{RESULTS}

The average age of respondents was 23 years, from which a majority declared had a relationship (73\%). Approximately $61 \%$ reported having middle school, a mediumhigh socioeconomic status $(48 \%)$ and the majority were unemployed with no health insurance $(82 \%)$. Regarding the type of delivery, $49 \%$ delivered by $\mathrm{C}$-section. Only 80 dyads (22\%) had no obstetric risk and the remaining $283(78 \%)$ had any obstetric risk. Relevantly, when asked about healthcare practices during delivery, high percentages of women received joint accommodation (93\%), skin-to-skin contact $(83 \%)$ and timely ligation of the umbilical cord $(93 \%)$. Nevertheless, only $63 \%$ of women breastfed within the first hour post-delivery and some reported perceiving sufficient quantity of milk production for their babies (37\%) (table 1).

The median time of follow-up (P25-P75) was 125 days (121-130 days), and the incidence rate of abandonment of breastfeeding was 8.9 per 1000 persons-days in the whole sample. When measuring the adjusted association between several factors and the maintenance of breastfeeding, there was a significant association between mothers' education and the interruption of breastfeeding $(\mathrm{p}<0.01)$. Thus, mothers with higher education were at 2.6 times higher risk (95\% CI: 1.2 to 5.9) of abandoning breastfeeding. Mothers within this category of education represented $18 \%$ of the total sample. While considering the socioeconomic conditions and relating these to access to water and sanitation services, $93 \%$ of women were eliminating excreta by toilet; nevertheless, the rest $(7 \%)$ who used a latrine were 1.8 times more likely to abandon breastfeeding, but this association was not statistically significant (95\% CI: 0.7 to 5.2 ) (table 2 ).

Results from the multivariate analysis indicated that the three most significant protective determinants of exclusive breastfeeding were (a) sessions of prenatal breastfeeding education ( $\mathrm{HR}=0.7 ; 95 \%$ CI: 0.5 to 0.9 ) per each extra session, (b) self-perception of milk production $(\mathrm{HR}=0.43 ; 95 \%$ CI: 0.31 to 0.59$)$ per each increase in the perceived quantity of milk production and (c) receiving early skin-to-skin contact (HR=0.1; $95 \%$ CI: 0.06 to 0.30$)$ when compared with those not receiving such contact immediately after birth (figure 1). Interestingly, adding other comprehensive healthcare practices and different to early skin-to-skin contact, to the models resulted in collinearity, thus, we excluded them from the modelling (online supplemental table 1S).

The effect of the determinants on time-to-abandonment did not change after stratifying by infant sex (online supplemental table $2 \mathrm{~S}$ ). Sensitivity analyses yielded very similar results; despite a stronger association between single marital status and time-to-abandonment (HR=6.5) when we excluded those dyads in which the infant delivered by C-section, the CI widened (95\% CI: 1.7 to 24.7), likely because there were only 10 single women who gave birth by caesarean delivery (online supplemental table $3 \mathrm{~S})$.

\section{DISCUSSION}

As several other studies have shown, many factors determine women's decisions to breastfeed their babies. ${ }^{18-20}$ Consequently, the duration of breastfeeding and the practices around it also vary. As this is the first study of this type to be conducted in this specific geographic region, it is the first to demonstrate that mothers' educational level, prenatal education on breastfeeding, early skin-to-skin contact and self-perception of milk production, appear to be strong determinants of exclusive breastfeeding in an urban population. However, when comparing the 
Table 1 Baseline characteristics

\begin{tabular}{|c|c|}
\hline Baseline characteristics* & Patients, $\mathrm{n}=363$ \\
\hline Mother's age (years), P50 (P25-P75) & 23 (19 to 28$)$ \\
\hline \multicolumn{2}{|l|}{ Mother's marital status } \\
\hline Single, $n(\%)$ & $24(7)$ \\
\hline With couple, n (\%) & $264(73)$ \\
\hline Separated, n (\%) & $10(3)$ \\
\hline Married, n (\%) & $60(17)$ \\
\hline Divorced, n (\%) & $4(1)$ \\
\hline Widow, n (\%) & $1(<1)$ \\
\hline \multicolumn{2}{|l|}{ Education } \\
\hline Without schooling, n (\%) & $1(<1)$ \\
\hline Basic education, $\mathrm{n}(\%)$ & $74(20)$ \\
\hline Middle education, n (\%) & $223(61)$ \\
\hline Higher education, n (\%) & $65(18)$ \\
\hline
\end{tabular}

Working status

\begin{tabular}{|c|c|}
\hline Full occupation, n (\%) & 33 \\
\hline Unemployment, n (\%) & 309 \\
\hline Underemployment, n (\%) & 21 \\
\hline \multicolumn{2}{|l|}{ Health insurance } \\
\hline Social security, n (\%) & $53(14)$ \\
\hline Other than social security, n (\%) & $13(4)$ \\
\hline None, n (\%) & $297(82)$ \\
\hline \multicolumn{2}{|l|}{ Socioeconomic conditions } \\
\hline Elimination of excreta by toilet, $\mathrm{n}(\%)$ & $337(93)$ \\
\hline Disposal of excreta by latrine, n (\%) & $26(7)$ \\
\hline \multicolumn{2}{|l|}{ Socioeconomic level† } \\
\hline High level, n (\%) & $70(19)$ \\
\hline Medium high, n (\%) & $175(48)$ \\
\hline Medium, n (\%) & $97(27)$ \\
\hline Medium low, n (\%) & $21(6)$ \\
\hline $\begin{array}{l}\text { Number of prenatal care office visits, P50 } \\
\text { (P25-P75) }\end{array}$ & $2(1-3)$ \\
\hline
\end{tabular}

(P25-P75)

Sessions of education about breastfeeding, P50 (P25-P75) Obstetric risk $\ddagger$

\begin{tabular}{|rr}
\hline No risk, $\mathrm{n}(\%)$ & $80(22)$ \\
\hline Low risk, $\mathrm{n}(\%)$ & $119(33)$ \\
\hline High risk, $\mathrm{n}(\%)$ & $125(34)$ \\
\hline Very high risk, $\mathrm{n}(\%)$ & $39(11)$ \\
\hline Type of delivery & $180(50)$ \\
\hline Eutocic vaginal delivery, $\mathrm{n}(\%)$ & $4(1)$ \\
\hline Dystocic vaginal delivery, $\mathrm{n}(\%)$ & $122(34)$ \\
\hline Elective C-section, $\mathrm{n}(\%)$ & $56(15)$ \\
\hline Emergent C-section, $\mathrm{n}(\%)$ & $302(83)$ \\
\hline Healthcare practice during delivery & $336(93)$ \\
\hline Skin-to-skin contact, $\mathrm{n}(\%)$ & $339(93)$ \\
\hline
\end{tabular}

Continued
Table 1 Continued

\begin{tabular}{|c|c|}
\hline Baseline characteristics* & Patients, $\mathrm{n}=363$ \\
\hline $\begin{array}{l}\text { Breastfeeding within the first hour of life, } \\
n(\%)\end{array}$ & $245(67)$ \\
\hline \multicolumn{2}{|l|}{ Infant variables } \\
\hline Male sex, n (\%) & $202(56)$ \\
\hline \multicolumn{2}{|l|}{ Gestational age, P50 (P25-P75) } \\
\hline Birth weight in g, mean (SD) & $3128(383)$ \\
\hline \multicolumn{2}{|l|}{ Self-perception of milk production } \\
\hline Very little quantity, n (\%) & $6(2)$ \\
\hline Little quantity, n (\%) & $50(14)$ \\
\hline Moderate quantity, n (\%) & $72(20)$ \\
\hline Enough quantity, n (\%) & $136(37)$ \\
\hline More than enough quantity, n (\%) & $99(27)$ \\
\hline
\end{tabular}

*The categories used (man=male gender) are the same as those collected by the National Institute of Statistics and Censuses. There were missing values in $<1 \%$ of the whole database. †The Graffar-Méndez Scale was applied; it uses the mother's level of instruction. Source of family income and housing conditions.

¥Obstetric risk was categorised according to the number of health risk conditions during pregnancy (ie, no risk=any condition, low risk=one condition, high risk=two conditions and very high risk=three or more conditions. $\mathrm{m}$, mean; SD, SD deviation.

effects of the different determinants on initiation and maintenance of exclusive breastfeeding, it is important to mention that various factors seem to act differentially between countries. ${ }^{21}$ Specifically, even if some studies ${ }^{22-24}$ evidenced that a low level of education is related to early abandonment of exclusive breastfeeding, some others, including our study, indicate the opposite, a fact that is consistent with data obtained from the 2012 National Health Survey demonstrating that mothers at both the lowest and highest socioeconomic strata (and probably more and less educated, respectively), have lower rates of exclusive breastfeeding compared with the intermediate strata. ${ }^{8}$

We speculate that the directionality of the association between education and breastfeeding could be due to the fact that current labour policies-with a direct impact on more educated mothers who might also have better chances of being fully occupied-are adverse for exclusive breastfeeding. In Ecuador, public and private institutions provide only up to 3 months of maternity leave, which precludes the practice of breastfeeding until 6 months. The application of maternity leave is not uniform, even among those with a full-time occupation. This makes it difficult to assess working status categories and represents a limitation that could explain why we did not detect a significant association between working status and exclusive breastfeeding. Additionally, women with higher socioeconomic status might tend to purchase breast-milk substitutes and consequently avoid exclusive breastfeeding. ${ }^{25}{ }^{26}$ Even if most women in our 
Table 2 Crude and adjusted HRs, estimated by mixed-effects Cox proportional hazards models per each explanatory variable Adjusted HRs (95\% Cl)

Explanatory variables

Crude HRs $(95 \% \mathrm{Cl})$

Parsimonious

\begin{tabular}{|c|c|c|c|c|c|c|}
\hline Explanatory variables & (95\% Cl) & P value & Saturated model & P value & model & $P$ value \\
\hline Mother's age (per each year of increasing) & $0.9(0.9$ to 1.0$)$ & 0.69 & $1.0(0.9$ to 1.1$)$ & 0.85 & - & - \\
\hline \multicolumn{7}{|l|}{ Mother's marital status } \\
\hline Single (other marital status reference) & $3.0(1.2$ to 7.6$)$ & 0.02 & 1.8 (0.5 to 6.4$)$ & 0.18 & 1.9 (0.6 to 6.1$)$ & 0.30 \\
\hline \multicolumn{7}{|l|}{ Education } \\
\hline $\begin{array}{l}\text { Higher education, (lower than higher is the } \\
\text { reference) }\end{array}$ & $1.9(0.9$ to 4.0$)$ & 0.07 & $3.0(1.3$ to 7.1$)$ & 0.01 & 2.6 (1.2 to 5.9$)$ & 0.01 \\
\hline Underemployment (otherwise is the reference) & $1.0(0.3$ to 3.2$)$ & 0.97 & $1.1(0.3$ to 4.0$)$ & 0.88 & - & - \\
\hline \multicolumn{7}{|l|}{ Socioeconomic conditions } \\
\hline $\begin{array}{l}\text { Disposal of excreta by latrine (otherwise is the } \\
\text { reference) }\end{array}$ & $3.5(1.5$ to 7.9$)$ & $<0.01$ & $2.0(0.7$ to 5.9$)$ & 0.19 & 1.8 (0.7 to 5.2$)$ & 0.21 \\
\hline $\begin{array}{l}\text { Sessions of breastfeeding education (per each extra } \\
\text { session) }\end{array}$ & $0.8(0.7$ to 1.1$)$ & 0.11 & 0.7 (0.5 to 0.9$)$ & 0.01 & 0.7 (0.5 to 0.9$)$ & 0.01 \\
\hline \multicolumn{7}{|l|}{ Healthcare practice during delivery ${ }^{*}$} \\
\hline Skin-to-skin contact (otherwise is the reference) & $0.2(0.1$ to 0.4$)$ & $<0.01$ & $0.2(0.1$ to 0.3$)$ & $<0.01$ & $0.1(0.06$ to 0.30$)$ & $<0.01$ \\
\hline Joint accommodation (otherwise is the reference) & $0.7(0.2$ to 1.9$)$ & 0.44 & - & - & - & - \\
\hline $\begin{array}{l}\text { Timely ligation of the umbilical cord (otherwise is } \\
\text { the reference) }\end{array}$ & $0.4(0.2$ to 1.1$)$ & 0.09 & - & - & - & - \\
\hline $\begin{array}{l}\text { Breastfeeding within the first hour of life (otherwise } \\
\text { is the reference) }\end{array}$ & $0.6(0.3$ to 1.2$)$ & 0.18 & - & - & - & - \\
\hline
\end{tabular}

Self-perception of milk production

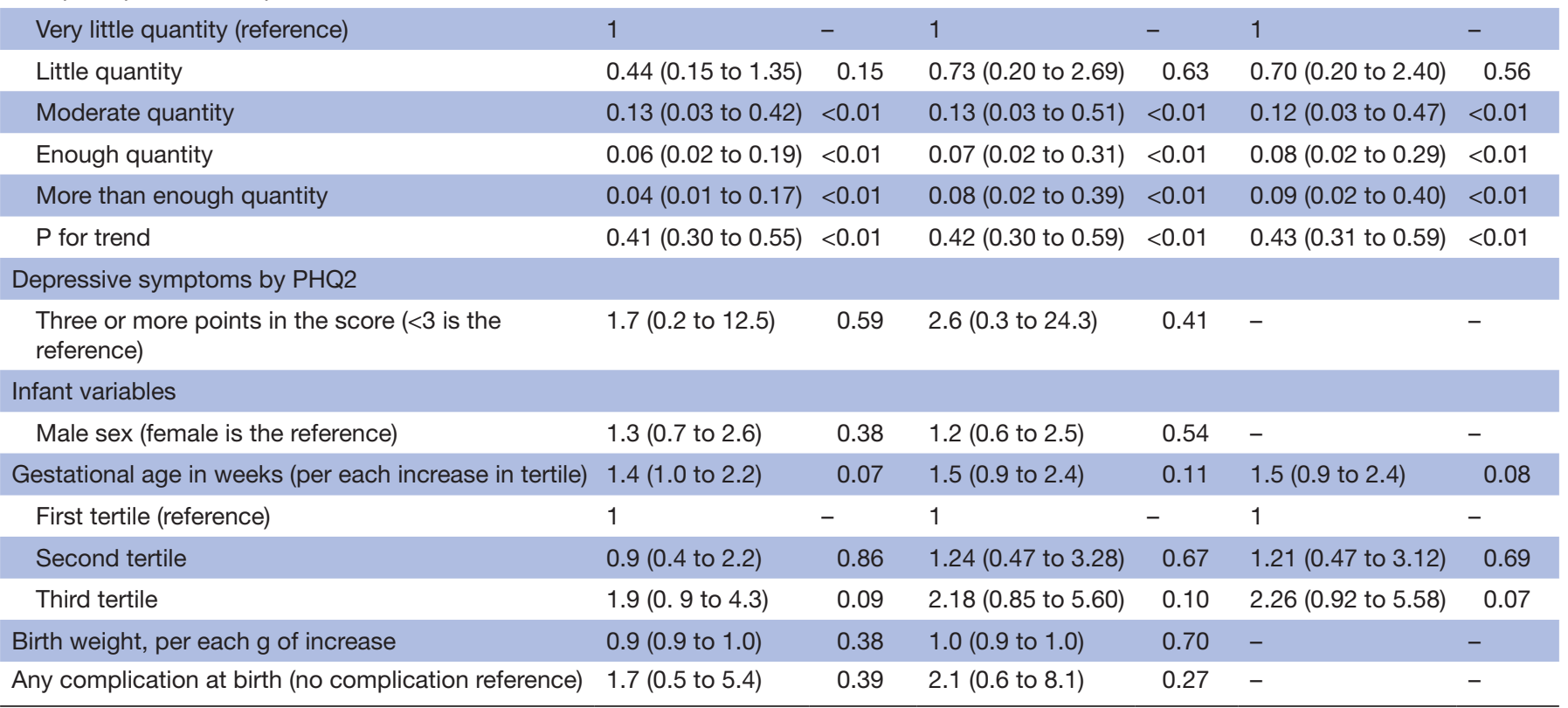

${ }^{*}$ There was found collinearity in the models between early skin-to-skin contact and: joint accommodation, timely ligation of the umbilical cord and breastfeeding within the first hour of life; those variables were excluded from modelling the saturated model (see online supplemental material for details).

PHQ2, Patient Health Questionnaire-2.

study were unemployed, there may be an association with the informal economy or unpaid housework, in which adequate maternity and workplace entitlements for breastfeeding are non-existent. Thus, diverse factors might be present in the association between unemployment and breastfeeding and no generalisation can be made, as these relationships might appear differently according to the context or the individual. 
Kaplan-Meier survival estimates of exclusive breastfeeding

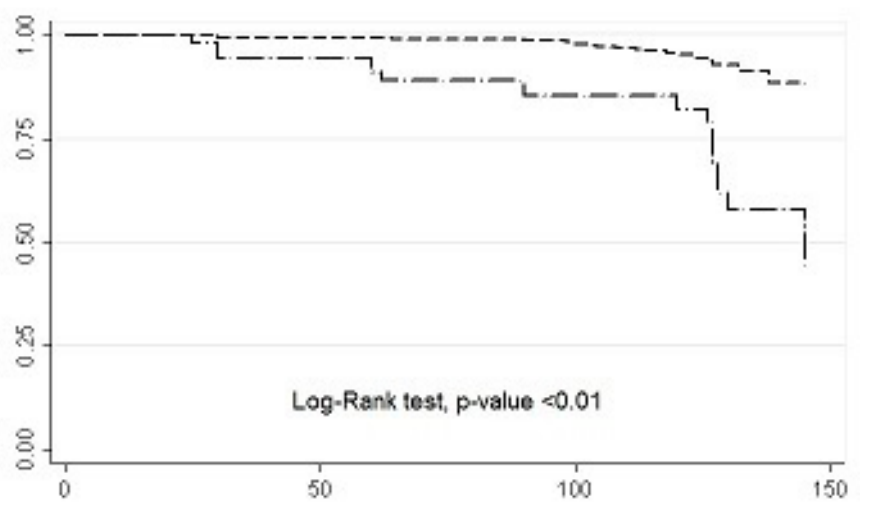

Anatris time in das or ife

- - - No eanty stin-to-sidn contact $\quad-----$ Eshy skin-to-skin contact

Figure 1 Kaplan-Meier survival estimates of duration of exclusive breastfeeding by early skin-to-skin contact categories.

Regarding the effect of prenatal care and education on breastfeeding on initiation and maintenance of exclusive breastfeeding, we consider our findings to be consistent with those from several other studies. ${ }^{22} 26-28$ Interestingly, we have circumscribed our study to the field of public healthcare, which represents approximately $60 \%$ of the total Ecuadorian healthcare. Even if public health facilities were strengthened regarding prenatal education, private institutions are not completely involved in this process; thus, further assessment of the implementation of the BFHI into private settings is necessary.

In addition, healthcare professionals should consider education, sociodemographic characteristics and cultural factors when counselling mothers to breastfeed. Furthermore, including male partners in the educational breastfeeding sessions could enhance adherence to exclusive breastfeeding practices, as indicated in a study conducted in the USA in which partners posed a positive effect on the mother's attitudes and intentions to breastfeed. ${ }^{29}$ Relevantly, the applicability of educative sessions should be performed on the antenatal and postnatal period, and the healthcare services provided accordingly.

Early skin-to-skin contact has been demonstrated as a strong determinant of exclusive breastfeeding by several studies and has been robustly demonstrated in a systematic review. ${ }^{13}$ A prospective cohort study conducted in Poland also contributed to this statement, by indicating that at least $30 \mathrm{~min}$ of skin-to-skin contact led babies to be exclusively breastfed for 1.2 months longer. Given that we observed collinearity between early skin-to-skin contact with each one of the other comprehensive health practices during delivery, obstetricians and general practitioners should consider assuring that, skin-to-skin contact is applied for every delivery, including cases of C-sections. This strategy should be accompanied by the initiation of breastfeeding within the first hour, mainly but not exclusively, for low birth weight and premature babies. ${ }^{21}$ To the best of our knowledge, this is the first study to demonstrate such an association in the Ecuadorian context.

It is interesting that perception of greater production of breast milk-a factor directly related to the practice of breastfeeding - is associated with a longer duration of exclusive breastfeeding. According to scientific evidence, up to $35 \%$ of women stopped breastfeeding during the first weeks of the postpartum period due to perceived insufficient milk production. ${ }^{30}$ We recommend that the association between the perception of breast-milk production and maintenance of exclusive breastfeeding should be further explored.

As the benefits of breastfeeding can be seen both short term and long term, mainly kin the social, economic and environmental spheres; national health authorities should work towards the promotion, protection and support of the practice with a special emphasis on the political advocacy at the multisectoral and intersectoral levels, leveraging financial investment, resource mobilisation and the organisation of supportive networks. A key example is the adaptation, implementation and evaluation of the BFHI. On the other hand, it is crucial to maintain and implement strong policies that restrict marketing of breast-milk substitutes, at the public and private levels, as also suggested by relevant scientific evidence. ${ }^{1}$

This was a longitudinal prospective study, developed under real-life conditions in an Ecuadorian urban population. Our estimates are calculated by proper adjustment of potential confounders, reducing potential sources of confounding bias. Probably, the most relevant limitation was the lack of representativeness of a rural population, in which determinants would be different. ${ }^{31}$ As our research analysed hospital data, another potential limitation is related to the population in the area that did not go or decided to not deliver in a health centre, considering accessibility and use of the health services as relevant factors. Nevertheless, in Ecuador, the annual rate of home delivery is less than $4 \% .^{32}$ Another potential limitation was the possible source of response bias, we employed phone surveys. Women may have tended to provide socially acceptable answers to please the interviewer. To minimise this source of bias, data collectors were appropriately trained in the methods.

We recognise that excluding illiterate individuals represents a limitation of our study, especially in the province of Manabi, which has a prevalence of illiteracy of $9.2 \%$. Unfortunately, with institutional ethical review board rules requiring patient notification and affirmative action for involvement in the studies, literacy was a condition to participation. Although ideally, informed consent is a process of sharing and discussing the risks and benefits of the research at hand, the culmination of the process is the signing of a written document by the research subject. Achieving appropriate readability and including all the required language in an informed consent document is a challenge not often won. Therefore, we cannot conclude 
if illiteracy could be a major determinant of breastfeeding in the current study.

Also, other potential confounders were not considered, like nutritional factors and biomarkers of nutritional wellbeing. Such nutritional status depends on the nutrient content of the consumed food, concerning the needs that are determined based on various factors such as age, sex, etc. ${ }^{33}$ Utilisation of nutrients access, and quality of food could be associated with different amounts of breast milk production and subsequently to the duration of breastfeeding. We did not assess such a relevant topic; however, we recognise that nutritional factors can be important determinants of breastfeeding. Future studies could focus on the effect of specific nutritional patterns or anthropometry on the initiation and maintenance of breastfeeding. Additionally, as the study focused on analysing the independent associations between social, educational, and health practice interventions as determinants of exclusive breastfeeding, further research related to motivational determinants and how cultural beliefs and practices influence the health-seeking behaviour of individuals and communities, is needed to complement the full panorama of breastfeeding determinants in this urban context.

Finally, Ecuador is a country with four different regions and immense diversity not only geographically, but socially, economically, culturally and ethnically. Although the findings may be applicable to some other similar contexts in the Ecuadorian Coast region, the results cannot be fully generalised to other regions with different socioeconomic, cultural or geographic contexts.

\section{CONCLUSION}

Prenatal education on breastfeeding, self-perception of sufficient breast-milk production and early skin-to-skin contact appear to be strong protectors of exclusive breastfeeding among urban Ecuadorian mother-baby dyads. Healthcare strategies, such as the BFHI, play a pivotal role in improving breastfeeding maintenance. In conclusion, to improve adherence to exclusive breastfeeding and enjoy the social and economic benefits, not only for the mother and the child but for the society as a whole, supportive policies from the healthcare, educational and economic fields are urgently needed.

\section{Author affiliations}

${ }^{1}$ Instituto de Salud Pública, Postgrado de Medicina Familiar y Comunitaria, Facultad de Medicina, Pontificia Universidad Católica del Ecuador, Quito, Ecuador

${ }^{2}$ Faculty of Medicine, Heidelberg Institute of Global Health, University of Heidelberg, Heidelberg, Germany

${ }^{3}$ Distrito 13D02, Centro de Salud San Juan, Ministerio de Salud Pública, Manta, Manabí, Ecuador

${ }^{4}$ Distrito 09d06, Ministerio de Salud Publica, Portoviejo, Manabí, Ecuador

${ }^{5}$ Zona 4 Manabí - Santo Domingo Distrito de Salud 13D11 Sucre - "San Vicente", Centro de Salud tipo A "San Clemente", Ministerio de Salud Publica, San Clemente, Ecuador

${ }^{6}$ Distrito 13D01, Centro de salud Palma Juntas y Centro de Salud de San Pablo, Ministerio de Salud Pública, San Pablo, Manabí, Ecuador
${ }^{7}$ Distrito de Salud 13d11, Centro de salud tipo A "San Andrés de Canoa", "San Vicente", Ministerio de Salud Pública, San Vicente-Sucre, Ecuador

${ }^{8}$ Zona 4 Manabí - Santo Domingo, Distrito de Salud 13d01 - Centro de Salud El Limón, Ministerio de Salud Pública, El Limón, Ecuador

'Distrito 13D01, Centro de Salud tipo A "Pimpiguasi", Ministerio de Salud Publica, Portoviejo, Ecuador

${ }^{10}$ Distrito de Salud 13d11, Centro de Salud Tipo A "Salinas", San Vicente-Sucre, Ministerio de Salud Publica, San Vicente-Sucre, Ecuador

${ }^{11}$ Distrito 13D04, Centro de Salud "Santa Ana", Ministerio de Salud Pública, Santa Ana, Manabí, Ecuador

${ }^{12}$ Centro de Salud Tipo A Carapungo 1, Ministerio de Salud Publica, Quito, Ecuador

Twitter Iván Dueñas-Espín @ivanduespin, David Menéndez @DrDavidMenendez, René Segovia @guillo2304 and Johanna Vinces @johys32

Acknowledgements Authors thank the Instituto de Salud Pública from Pontificia Universidad Católica del Ecuador for their input. We would like to thank Editage ( www.editage.com) for English language editing.

Contributors IDE takes responsibility for (is the guarantor of) the content of the manuscript. IDE, ÁL-C, AÁ, JA, KF, VL, WL, MM, DM, EM, RS and JV contributed to (a) planning, conducting, and reporting the work, (b) the conception, design of the study, acquisition of the data, analyses and interpretation of results, (c) critically revised the article, (d) approved the final version to be published and (e) agreed to be accountable for all aspects of the work.

Funding The authors have not declared a specific grant for this research from any funding agency in the public, commercial or not-for-profit sectors.

Competing interests None declared.

Patient consent for publication Not required.

Ethics approval This study was conducted with the Research Ethics Committee in Human of the Pontificia Universidad Católica del Ecuador approval (code number: 2018-48-E0).

Provenance and peer review Not commissioned; externally peer reviewed.

Data availability statement Data are available upon reasonable request. The project is currently making available the main study results and data by making a request through the correspondence author.

Supplemental material This content has been supplied by the author(s). It has not been vetted by BMJ Publishing Group Limited (BMJ) and may not have been peer-reviewed. Any opinions or recommendations discussed are solely those of the author(s) and are not endorsed by BMJ. BMJ disclaims all liability and responsibility arising from any reliance placed on the content. Where the content includes any translated material, BMJ does not warrant the accuracy and reliability of the translations (including but not limited to local regulations, clinical guidelines, terminology, drug names and drug dosages), and is not responsible for any error and/or omissions arising from translation and adaptation or otherwise.

Open access This is an open access article distributed in accordance with the Creative Commons Attribution Non Commercial (CC BY-NC 4.0) license, which permits others to distribute, remix, adapt, build upon this work non-commercially, and license their derivative works on different terms, provided the original work is properly cited, appropriate credit is given, any changes made indicated, and the use is non-commercial. See: http://creativecommons.org/licenses/by-nc/4.0/.

\section{ORCID iDs}

Iván Dueñas-Espín http://orcid.org/0000-0002-6639-727X

Ángela León Cáceres http://orcid.org/0000-0002-4517-9409

\section{REFERENCES}

1 Rollins NC, Bhandari N, Hajeebhoy N, et al. Why invest, and what it will take to improve breastfeeding practices? Lancet 2016;387:491-504.

2 Victora CG, Horta BL, Loret de Mola C, et al. Association between breastfeeding and intelligence, educational attainment, and income at 30 years of age: a prospective birth cohort study from Brazil Lancet Glob Health 2015;3:e199-205.

3 Richards M, Hardy R, Wadsworth MEJ. Long-term effects of breastfeeding in a national birth cohort: educational attainment and midlife cognitive function. Public Health Nutr 2002;5:631-5.

4 Hoddinott P, Tappin D, Wright C. Breast feeding. BMJ 2008;336:881-7. 
5 Victora CG, Bahl R, Barros AJD, et al. Breastfeeding in the 21st century: epidemiology, mechanisms, and lifelong effect. Lancet 2016;387:475-90.

6 Yngve A, Sjöström M. Breastfeeding determinants and a suggested framework for action in Europe. Public Health Nutr 2001;4:729-39.

7 Jara-Palacios Miguel Á., Cornejo AC, Peláez GA, et al. Prevalence and determinants of exclusive breastfeeding among adolescent mothers from Quito, Ecuador: a cross-sectional study. Int Breastfeed J 2015;10:1-8.

8 Belmont P, Ramírez-Luzuriaga MJ, Freire WB, et al. Encuesta Nacional de salud Y Nutrición. ENSANUT-ECU 2012, 2014.

9 IBFAN, WHO. Marketing of breast-milk substitutes: national implementation of the International Code 2020.

10 Ministerio de Salud Pública. Establecimientos de salud amigos de la madre Y del niño (ESAMyN), 2017. Available: https://www.salud. gob.ec/establecimientos-de-salud-amigos-de-la-madre-y-del-ninoesamyn/ [Accessed 6 Jun 2018].

11 INEC. Resultados del censo de población Y vivienda Fascículo provincial Manabí. Inec 2010:1-7.

12 WHO. Baby-friendly hospital initiative, 2018.

13 Moore ER, Anderson GC, Bergman N, et al. Early skin-to-skin contact for mothers and their healthy newborn infants. Cochrane Database Syst Rev 2012:CD003519.

14 World Health Organization. Indicators for assessing infant and young child feeding practices. World Heal Organ 2007;2007:1-19.

15 Graffar M. Une méthode de classification sociale d'échantillons de population. Courrier1956.

16 Schoenfeld DA. Sample-size formula for the proportional-hazards regression model. Biometrics 1983;39:499.

17 Harrell FE. Regression modeling strategies 2003;45.

18 Lesorogol C, Bond C, Dulience SJL, et al. Economic determinants of breastfeeding in Haiti: the effects of poverty, food insecurity, and employment on exclusive breastfeeding in an urban population. Matern Child Nutr 2018;14:1-9.

19 Hamade H, Chaaya M, Saliba M, et al. Determinants of exclusive breastfeeding in an urban population of primiparas in Lebanon: a cross-sectional study. BMC Public Health 2013;13:702.

20 Kimani-Murage EW, Madise NJ, Fotso J-C, et al. Patterns and determinants of breastfeeding and complementary feeding practices in urban informal settlements, Nairobi Kenya. BMC Public Health 2011;11:396.
21 Patel A, Bucher S, Pusdekar Y, et al. Rates and determinants of early initiation of breastfeeding and exclusive breast feeding at 42 days postnatal in six low and middle-income countries: a prospective cohort study. Reprod Health 2015;12:S10.

22 Senanayake P, O'Connor E, Ogbo FA. National and rural-urban prevalence and determinants of early initiation of breastfeeding in India. BMC Public Health 2019;19:1-13.

23 Sajjad S, Roshan R, Tanvir S. Impact of maternal education and source of knowledge on breast feeding practices in Rawalpindi City. MOJCRR 2018;1:212-42.

24 Lawson K, Tulloch MI. Breastfeeding duration: prenatal intentions and postnatal practices. J Adv Nurs 1995;22:841-9.

25 Tang K, Wang $\mathrm{H}$, Tan SH, et al. Association between maternal education and breast feeding practices in China: a population-based cross-sectional study. BMJ Open 2019;9:e028485-9.

26 Chipojola R, Lee GT, Chiu H-Y, et al. Determinants of breastfeeding practices among mothers in Malawi: a population-based survey. Int Health 2020;12:132-41.

27 Woldeamanuel BT. Trends and factors associated to early initiation of breastfeeding, exclusive breastfeeding and duration of breastfeeding in Ethiopia: evidence from the Ethiopia demographic and health survey 2016. Int Breastfeed J 2020;15:1-13.

28 Cozma-Petrut A, Badiu-Tișa I, Stanciu O, et al. Determinants of early initiation of breastfeeding among mothers of children aged less than 24 months in northwestern Romania. Nutrients 2019;11 doi:10.3390/ nu11122988

29 Mitchell-Box K, Braun KL, Hurwitz EL, et al. Breastfeeding attitudes: association between maternal and male partner attitudes and breastfeeding intent. Breastfeed Med 2013;8:368-73.

30 Gatti L. Maternal perceptions of insufficient milk supply in breastfeeding. J Nurs Scholarsh 2008;40:355-63.

31 Hernández-Cordero S, Lozada-Tequeanes AL, Fernández-Gaxiola $A C$, et al. Barriers and facilitators to breastfeeding during the immediate and one month postpartum periods, among Mexican women: a mixed methods approach. Int Breastfeed J 2020;15:1-12.

32 Instituto Nacional de Estadística Y Censos, Estadísticas Vitales. Registro Estadístico de Nacidos Vivos Y Defunciones Fetales 2019, 2020.

33 Pedraza DF. Estado nutricional como factor $Y$ resultado de la seguridad alimentaria $Y$ nutricional $Y$ Sus representaciones en Brasil. Rev Salud Pública 2004;6:140-55. 